\title{
A SUCESSÃO TRABALHISTA NAS ATIVIDADES NOTARIAL E REGISTRÁRIA APÓS A CONSTITUIÇÃO FEDERAL DE 1988
}

\author{
LABOR SUCCESSION IN THE CONTEXT OF EXTRAJUDICIAL NOTARY \\ AFTER BRAZILIAN FEDERAL CONSTITUTION OF 1988 \\ Victor Hugo Almeida \\ Faculdade de Ciências Humanas e Sociais da Universidade Estadual Paulista - UNESP _ \\ Franca - São Paulo - Brasil
}

\begin{abstract}
Resumo: Os setenta anos de vigência da Consolidação das Leis do Trabalho não bastaram para encerrar todas as controvérsias sobre a sucessão trabalhista. Com a promulgação da Constituição Federal de 1988, o ingresso nas atividades notarial e registrária passou a ser condicionado à aprovação em concurso público, conforme o artigo 236, parágrafo $3^{\circ}$, cuja norma apenas foi regulamentada em 1997, através da Lei dos Cartórios (8.935/97). Este artigo tem por objetivo examinar a sucessão trabalhista nas atividades notarial e registrária após a Constituição Cidadã, explorando especificamente: a (i)legitimidade passiva dos cartórios extrajudiciais para figurar em reclamações trabalhistas e a (in)ocorrência de sucessão trabalhista nos casos em que a relação de emprego foi extinta em período anterior à outorga da delegação por concurso público. Como método de procedimento, adotou-se a técnica de pesquisa bibliográfica e, quanto ao método de abordagem, optou-se pelo método de caso e o indutivo. O estudo concluiu pela caracterização da sucessão trabalhista nas atividades registrária e notarial apenas quando houver continuidade da prestação em benefício do novo oficial/notário, devendo responder pelos créditos trabalhistas o próprio titular e não a unidade cartorária, em razão da sua condição de ente despersonalizado.
\end{abstract}

Palavras-chave: Cartórios extrajudiciais - Delegação - Responsabilidade Sucessão trabalhista.

Abstract: The seventy years of the Consolidation of Labor Laws was not enough to end all disputes on labor succession. With the promulgation of the Federal Constitution of 1988, the admission to the notarial and registration activities became conditioned to approval by public concourse, in accordance with article 236, paragraph 3, whose rule was only regulated in 1997 by the Notary Law (8935/97). This article aims to examine the labor succession in notarial and registration activities after the Citizen Constitution, specifically exploring: the passive (il)legitimacy of extrajudicial notary to figure in labor claims and the occurrence of labor succession where the employment relationship was extincted in a prior period to the granting of the delegation by public concourse. As a method of procedure, it was adopted the rules of bibliographical research and, as a method of approach, we chose the case method and the inductive. The study concluded by characterizing the labor succession in notarial and registration activities only when there is continuity of provision for the benefit of the new officer/notary and must respond by labor 
credits the holder itself and not the notarial unit, because of their condition depersonalized entity.

Keywods: Extrajudicial notary - Labor succession - Responsibility - Delegation.

\section{Considerações iniciais}

Com a promulgação da Constituição da República Federativa do Brasil de 1988, o ingresso nas atividades notarial e registrária passou a ser condicionado à aprovação em concurso público de provas e títulos, conforme prevê o artigo 236, parágrafo 3ํㅡㄹ da Constituição Cidadã. A regulamentação desse dispositivo constitucional surgiu apenas mais tarde, com a aprovação da Lei no 8.935, de 18 de novembro de 1994, a Lei dos Cartórios, composta por cinquenta e cinco artigos que dispõem sobre os serviços notariais e registrários.

Antes, porém, as escrivanias e os tabelionatos pertenciam a particulares que exerciam o munus público através da investidura pelo Estado, visando desafogar a Administração Pública por meio da delegação.

Embora esclareça Hely Lopes Meirelles (1996) que a delegação ocorre por meio de licitação, sob regime de concessão ou permissão a um particular (pessoa física ou jurídica), a delegação para a exploração das atividades notarial e registrária, antes da Constituição Federal de 1988, se assemelhava ao ato negocial de compra e venda ou se transmitia por herança, sem sujeição a licitação.

Todavia, a Constituição Federal alterou as regras para a delegação do munus público. O caput do artigo 236 da Constituição Federal de 1988 manteve o regime de exercício dos serviços notarial e registrário em caráter privado, por delegação do Poder Público. Porém, com a exigência da investidura por concurso público, os titulares ingressados antes do advento constitucional foram mantidos nas serventias, conservando a titularidade das escrivanias e dos tabelionatos.

Igual sorte não alcançaram os notários e registrários substitutos que até então administravam e respondiam pela unidade cartorária, os quais 
permaneceram nas serventias apenas até a efetivação de nova delegação, dessa vez, através de concurso público de provas e títulos, consoante à regra inaugurada pelo artigo 236, parágrafo 3ํㅡㄹ da Constituição Federal de 1988.

Com isso, considerando a unicidade do ordenamento jurídico e sua intradependência, os impactos dessas alterações alcançaram o Direito do trabalho, especificamente no tocante à sucessão trabalhista. Em alguns casos, os candidatos aprovados em concurso público de provas e títulos para outorga de delegações de notas e de registros estaduais foram surpreendidos ao assumirem serventias abarrotadas de processos trabalhistas ajuizados anteriormente à investidura.

Todavia, os setenta anos de vigência da Consolidação das Leis do Trabalho, aprovada pelo Decreto-Lei ํㅜ 5.452 , de $1^{\circ}$ de maio de 1943 , não bastaram para oferecer guarida aos novos delegados. Os únicos dispositivos celetistas sobre a matéria sucessória (artigos 10 e 448) dispõem apenas que a alteração na propriedade ou na estrutura jurídica da empresa não afetará os contratos de trabalho e os direitos adquiridos pelos empregados. Porém, a atividade notarial e registrária em nada se assemelham à atividade empresarial; tratam-se de atividades administrativas delegadas pelo Poder Público e remuneradas através de custas e emolumentos.

Com o tempo, os pormenores para a caracterização da sucessão trabalhista foram decantados pelo esforço jurisprudencial e doutrinário, haja vista que a própria Consolidação das Leis do Trabalho pouco avançou nesse assunto. Porém, diante do recorte apresentando, o assunto retornou à pauta de discussões após as alterações operadas pela Constituição Federal de 1988 sobre a delegação dos cartórios extrajudiciais, impulsionando a transmissão de serventias em todo o país, muitas delas endividadas e oneradas por um expressivo passivo trabalhista.

Este artigo tem por objetivo examinar os seguintes pontos sobre o tema: (a) a (i)legitimidade passiva dos cartórios extrajudiciais em reclamações trabalhistas; e (b) a (in)ocorrência de sucessão trabalhista em situação de extinção da relação de emprego antes da outorga da delegação ao candidato aprovado em concurso público. 
Quanto à metodologia, como método de procedimento, adotou-se a técnica de pesquisa bibliográfica em materiais já publicados (artigos, legislação, doutrinas, sítios eletrônicos, jurisprudência, etc.) e, como método de abordagem, optou-se pelos métodos de caso e o indutivo, com a finalidade de extrair conclusões gerais acerca da caracterização desse instituto no contexto abordado (atividades notarial e registrária).

\section{Breves considerações sobre a sucessão trabalhista à luz da Consolidação das Leis do Trabalho}

A Consolidação das Leis do Trabalho não se ocupou da definição do instituto sucessório trabalhista, tampouco da especificação dos seus elementos caracterizadores. Sucinta, a legislação trabalhista apenas se limitou em advertir sobre a preservação do contrato de trabalho e dos direitos adquiridos pelos empregados em caso de alteração na estrutura jurídica ou na propriedade da empresa, consoante ao que se extrai dos artigos 10 e 448 da Consolidação das Leis do Trabalho.

A composição de um rol de elementos indicativos da caracterização de sucessão trabalhista coube à doutrina, que definiu alguns parâmetros para se concluir ou não pela responsabilização do sucessor pelos créditos trabalhistas inadimplidos pelo empregador sucedido.

Amparado na Consolidação das Leis do Trabalho, Maurício Godinho Delgado (2009) esclarece que a sucessão de empregadores, como instituto justrabalhista previsto nos artigos 10 e 448 da Consolidação das Leis do Trabalho, diz respeito à transferência da titularidade da empresa ou estabelecimento, por meio da qual se opera uma completa transmissão de créditos e dívidas do alienante (sucedido) para o adquirente (sucessor).

Homero Batista Mateus da Silva (2009), por meio de uma abordagem comparativa entre Direito do Trabalho e Direito Civil, esclarece que, enquanto a sucessão na perspectiva civil se relaciona à morte de um dos sujeitos, na perspectiva laboral está mais relacionada à disposição do estabelecimento empresarial ou industrial com vista à manutenção das condições originais. 
Certo é que, consoante ao disposto no artigo $2^{\circ}$ da Consolidação das Leis do Trabalho, empregador é a empresa e não seus respectivos sócios titulares (NASCIMENTO, 2011). Assim sendo, em casos de transmissão da propriedade do estabelecimento empresarial o empregador permanece o mesmo, qual seja, a pessoa jurídica, havendo mudança apenas na estrutura ou na propriedade da empresa (MARTINS, 2012).

Vólia Bomfim Cassar (2011) elenca alguns elementos caracterizadores da sucessão trabalhista, percorrendo, inclusive, os efeitos dela decorrentes. Nesse sentido, aponta que a sucessão pode ocorrer de forma provisória ou definitiva, a título público ou privado, graciosa ou onerosamente, importando de fato a continuidade da exploração pelo sucessor da atividade econômica explorada anteriormente pelo sucedido.

Para Cassar (2011, p. 479), pouco importa a continuidade da prestação pelo empregado, haja vista que o novo titular (sucessor) responde tanto pelas obrigações trabalhistas dos contratos em execução como daqueles que se extinguiram antes da transferência da titularidade empresarial. Isto porque 0 contrato de trabalho apenas é intuito personae em relação ao empregado e não ao empregador.

Superada essa primeira abordagem conceitual sobre o tema, necessário se faz o exame dos requisitos caracterizadores da sucessão trabalhista sob a perspectiva contextual das atividades notarial e registrária, conforme proposto neste estudo.

\section{Requisitos caracterizadores da sucessão trabalhista na perspectiva das atividades notariais e registrárias}

Pontua Otavio Pinto e Silva (2010, p. 143) que "a sucessividade do contrato de trabalho frequentemente faz surgir o problema da definição da responsabilidade dos sócios atuais e antigos pelas dívidas trabalhistas assumidas pela sociedade", no caso em estudo, pelo oficial ou notário antecessor ao novo titular investido por concurso público.

Para Délio Maranhão (1983), a caracterização da sucessão na esfera trabalhista é condicionada à observância de dois requisitos: a transferência da 
unidade econômico-jurídica de um para outro titular e a inexistência de ruptura na prestação de serviços pelo empregado.

Consoante à doutrina clássica, são requisitos para a sucessão: (a) a transferência total ou parcial da empresa ou do estabelecimento ou a transferência de unidade econômico-jurídica; (b) a continuidade do empreendimento; e (c) a continuidade da prestação de serviços (CASSAR, 2011; MARTINS, 2012; MARTINEZ, 2011; DELGADO, 2009; NASCIMENTO, 2011).

Quanto ao primeiro requisito, entende-se por transferência total ou parcial da empresa ou do estabelecimento (ou a transferência de unidade econômico-jurídica) a transmissão do todo ou de um ou alguns estabelecimentos específicos (filial, agência, etc.), independentemente do título jurídico da transferência (público ou privado; gratuita ou onerosa). Tal transferência deve, ao menos, abranger uma significativa fração empresarial que traduza a noção de unidade econômico-jurídica (instalações, máquinas, matéria-prima, trabalhadores, etc.), sendo certo que a mera transferência de bens singulares (por exemplo: uma máquina, dois equipamentos, algumas ferramentas, etc.) não se traduz em sucessão trabalhista.

Sérgio Pinto Martins (2012) esclarece que o contrato de trabalho segue o estabelecimento, portanto, a transferência do estabelecimento importa em sucessão na perspectiva laboral.

Todavia, divergem dessa concepção Vólia Bomfim Cassar (2011) e Luciano Martinez (2011) ao sustentarem que esse não é o único requisito, pois o simples fato de uma empresa explorar um local já utilizado por outra distinta não atrai a sucessão trabalhista.

Todavia, no que tange às atividades notarial e registrária, o recebimento da unidade cartorária pelo delegado aprovado em concurso ocorre de forma originária por ato do Poder Público, nos termos previstos no artigo 236 da Constituição Federal. Conquanto a doutrina seja vacilante nesse ponto, posiciona-se favoravelmente a Corregedoria Geral de Justiça de São Paulo ao registrar, nos autos do Processo n- CG-855/2003, que as obrigações referentes ao serviço extrajudicial competem à pessoa do delegado ou, na vacância, ao 
Estado, o real titular; jamais ao novo titular, que aprovado no concurso, recebe investidura originária, ou seja, do próprio Estado.

No mesmo sentido posiciona-se o Tribunal Superior do Trabalho, inovando a matéria ao se atentar que, em se tratando de serventia cartorial, não há transferência de um direito, mas sim uma aquisição originária de direitos por aprovação em concurso público, afastando a afiguração da sucessão trabalhista prevista nos artigos 10 e 448 da Consolidação das Leis do Trabalho (TRIBUNAL SUPERIOR DO TRABALHO, 2010). Assim, em se tratando de atividades notarial e registária, não ocorre uma transmissão direta pelo antigo titular, pois, ao deixar o cargo, o Poder Público retoma a delegação da atividade, interrompendo a cadeia sucessória por meio do certame.

Essa noção também afasta a caracterização do requisito da transferência total ou parcial da empresa ou estabelecimento, pois, com a ruptura da cadeia sucessória pela retomada da delegação pelo Poder Público, não há que se falar em transferência direta pelo antigo delegado substituto. Isto porque, se os serviços notarial e registrário são públicos e pertencem ao Estado (jamais ao particular), logo, não são cessíveis. Desta feita, o que não é cessível não é suscetível de sucessão.

Do mesmo modo, não se caracterizando como empresa ou entidade, se o cartório extrajudicial é uma instituição administrativa desprovida de personalidade jurídica, de capacidade processual e de patrimônio próprio, inexiste também transferência de unidade econômico-jurídica capaz de configurar uma sucessão trabalhista. Nesse sentido já se pronunciou o Supremo Tribunal Federal, esclarecendo que o serventuário não é dono da serventia e, por isso, não pode transferi-la (SUPREMO TRIBUNAL FEDERAL, 2012).

Ademais, consoante ao entendimento da 4⿳亠丷厂 Turma do Tribunal Regional do Trabalho da $3^{\text {a }}$ Região, os cartórios extrajudiciais também não exercem atividade empresarial e não se caracterizam como empreendimento econômico, merecendo, portanto, tratamento diferenciado em relação àqueles que exercem profissionalmente atividade organizada para a produção e troca de bens e serviços, ao passo que seu titular exerce atividade pública de natureza administrativa, percebendo remuneração através de custas e REVISTA DO DIREITO UNISC, SANTA CRUZ DO SUL №. 43 | p.55-72 | MAIO-AGO 2014 
emolumentos pela prestação de serviços públicos (TRIBUNAL REGIONAL DO TRABALHO 3ㄹ REGIAÃO, 2003).

Por fim, não se pode ignorar que, enquanto nas empresas a sucessão se opera através da transferência de todos os elementos que compõem a unidade empresarial (capital social, fundo de comércio, etc.), criando direitos e obrigações, nos cartórios extrajudiciais o novo titular é nomeado por meio de outorga de delegação do Estado, precedida por concurso público, inexistindo alienação ou cessão empresarial, bem como transmissão do capital social entre o antigo e o novo titular.

O segundo requisito, a continuidade do empreendimento, diz respeito à manutenção pelo sucessor da exploração da mesma atividade econômica do sucedido. Para Evaristo de Moraes Filho (1960) e Süssekind (2002), o novo titular deve, no dia seguinte, prosseguir com a exploração da atividade empresarial, sem qualquer paralisação ou interrupção.

Discorda Vólia Bomfim Cassar (2011) ao aduzir que a paralisação por um breve período, desde que não implique na extinção da atividade, não impede a sucessão. Ademais, alerta Sérgio Pinto Martins (2012) que deve o sucessor explorar a mesma atividade econômica do sucedido, sendo essa a posição jurisprudencial majoritária, não bastando que seja apenas similar ou conexa, conforme diverge parte da doutrina.

O terceiro e último requisito caracterizador da sucessão trabalhista, a continuidade da prestação de serviços, diz respeito à necessidade da continuidade da prestação laborativa pelo empregado em benefício do sucessor. A controvérsia quanto à aplicabilidade desse último requisito comporta duas correntes doutrinárias.

A primeira corrente sustenta que há sucessão trabalhista mesmo que 0 obreiro não tenha se ativado para o novo titular, ou seja, é dispensável a continuidade da prestação do serviço, pois a energia aplicada naquela atividade se prorroga no tempo e dela se beneficia o novo titular. Para Vólia Bomfim Cassar (2011), pouco importa a continuidade da prestação dos serviços, pois o novo titular responde tanto pelas obrigações trabalhistas dos contratos em curso como daqueles que se extinguiram antes da transferência 
da titularidade da empresa, uma vez que o contrato de trabalho não é intuito personae em relação ao empregador.

Contudo, por mais que o antigo empregado tenha aplicado sua energia naquela atividade, essa energia não se prorroga no tempo, já que no caso específico dos cartórios de registro de imóveis a quantidade de clientes não depende diretamente do esforço dos funcionários, mas sim da delimitação da atuação territorial. Assim, não se pode argumentar que graças ao trabalho daquele antigo empregado, o novo titular estaria hoje recebendo mais custas e emolumentos, já que a competência da atividade registrária de imóveis é territorial.

Esse mesmo argumento pode não ser aproveitado em benefício dos tabelionatos de notas, cujos resultados econômicos dependem da satisfação da clientela, um das formas de fidelização de clientes, admitindo-se, portanto, a concorrência entre tabelionatos, o que não é possível no caso dos cartórios de registro de imóveis.

A segunda corrente, mais coerente na nossa perspectiva, integrada por Maurício Godinho Delgado (2009) e Homero Batista Mateus da Silva (2009), sustenta que a sucessão trabalhista só se verificará se houver continuidade da prestação laborativa para o novo titular.

Talvez seja esse o requisito menos polêmico na perspectiva em discussão, embora seja a pedra de toque da caracterização da sucessão trabalhista nas atividades notariais e registrárias. Isto porque há consenso, tanto jurisprudencial como doutrinário, no sentido de afastar a responsabilidade dos delegados aprovados em concurso público (sucessores) pelas verbas trabalhistas referentes a contratos de trabalho já extintos antes da outorga, exatamente pela inexistência de continuidade da prestação laborativa em benefício do delegado sucessor. Nesse caso, não deve o novo titular aprovado em concurso público ser responsabilizado, justamente por não ter se beneficiado do labor de um empregado que jamais conheceu, em razão da ruptura do contrato de trabalho ter ocorrido em período anterior à investidura.

Portanto, entendemos pela descaracterização da sucessão trabalhista nos casos de contratos de trabalho já extintos ou processos trabalhistas referentes a período laboral anterior à outorga, sob a justificativa de que a REVISTA DO DIREITO UNISC, SANTA CRUZ DO SUL №. 43 | p.55-72 | MAIO-AGO 2014 
caracterização da sucessão trabalhista decorre do preenchimento dos respectivos requisitos sucessórios, embora saliente Sérgio Pinto Martins (2012, p. 214) que "para o Direito do Trabalho a sucessão tem um aspecto mais econômico do que jurídico".

Essa concepção passou a sustentar nova vertente do instituto sucessório trabalhista, que, segundo Delgado (2009), assenta-se apenas em uma premissa essencial: qualquer mudança intra ou interempresarial que não venha afetar os contratos de trabalho, independentemente da continuidade ou não da prestação laborativa.

Evidentemente, essa vertente advoga mais para os interesses dos empregados, ao se desprender do tecnicismo tradicional para a caracterização da sucessão trabalhista. Porém, nas atividades analisadas, quais sejam, notarial e registrária, seria perverso exigir que o sucessor (aprovado em concurso público), que não tem condições de averiguar o passivo trabalhista das serventias disponíveis no ato da escolha, fosse responsabilizado pela ingerência do sucedido, bem como do Poder Público, que se desvencilhou do seu encargo fiscalizatório.

Ainda, conforme apregoa o artigo 236, caput, da Constituição Federal, não se pode esquecer que os serviços notarial e registrário são exercidos em caráter privado, por delegação do Poder Público, a quem cabe a responsabilidade fiscalizatória durante e ao final do exercício pelo sucedido da atividade que the fora delegada.

\section{Aspectos legais da sucessão trabalhista nas atividades notariais e registrarias}

Preleciona o artigo 236, caput, da Constituição Federal de 1988, que "os serviços notariais são exercidos em caráter privado, por delegação do Poder Público". Em complemento, dispõe o artigo 20 da Lei no 8.935/94, que regula tais atividades, que cabe aos notários e oficiais de registro, no desempenho de suas funções, a contratação de escreventes e auxiliares como empregados sob o regime celetista, cuja remuneração será ajustada livremente entre as partes. 
Extrai-se, assim, tanto do dispositivo constitucional como do infraconstitucional, que a relação de emprego se dá entre o empregado e o oficial ou notário, jamais entre o empregado e o cartório extrajudicial, por ser este último desprovido de personalidade jurídica, nos termos do artigo 236 da Constituição Cidadã. Ainda assim, não é raro encontrar empregados registrados no nome da unidade cartorária, bem como reclamações trabalhistas tendo em seu polo passivo a serventia e não o oficial ou notário.

Os artigos 21 e 22 da Lei no 8.935/94 encerram quaisquer dúvidas a respeito da ilegitimidade do cartório extrajudicial para contratar e figurar como parte de qualquer processo judicial ou administrativo, ao estabelecerem, respectivamente, a responsabilidade do titular pelo gerenciamento administrativo e financeiro, bem como pelos danos que causarem, incluindo seus prepostos, a terceiros, por culpa ou dolo, na prática de atos próprios da serventia.

Ainda na mesma direção, a Corregedoria Geral de Justiça do Estado de São Paulo, por meio do Processo nº CG-855/2003, já se pronunciou que as obrigações relacionadas ao serviço extrajudicial competem à pessoa do delegado e, na vacância, ao Estado, o verdadeiro titular dessa prestação, haja vista que o candidato aprovado em concurso público recebe a serventia de forma derivada e não diretamente do titular que o precedeu; por isso, não há que se falar em responsabilidade do delegado sucessor pelos créditos trabalhistas inadimplidos pelo sucedido, por inexistir vínculos anteriores que 0 responsabilize pelas obrigações preexistentes.

Recorte-se, ainda, o posicionamento prevalente do Tribunal Superior do Trabalho:

SUCESSÃO TRABALHISTA - TITULAR DE CARTÓRIO EXTRAJUDICIAL - POSSIBILIDADE - RESPONSABILIDADE DO SUCESSOR 1. A sucessão trabalhista opera-se sempre que a pessoa do empregador é substituída na exploração do negócio, com transferência de bens e sem ruptura na continuidade da atividade empresarial. 2. O cartório extrajudicial não possui personalidade jurídica própria. Desse modo, seu titular é o responsável pela contratação, remuneração e direção da prestação dos serviços, equiparando-se, pois, ao empregador comum, sobretudo porque aufere renda proveniente da exploração das atividades do cartório. 3 . Assim, a alteração da titularidade do serviço notarial, com a correspondente transferência da unidade econômico-jurídica que 
integra o estabelecimento, além da continuidade na prestação dos serviços, caracteriza a sucessão de empregadores. 4 - Destarte, a teor dos artigos 10 e 448 da CLT, o Tabelião sucessor é responsável pelos direitos trabalhistas oriundos das relações laborais vigentes à época do repasse, bem como pelos débitos de igual natureza decorrentes de contratos já rescindidos. (TRIBUNAL SUPERIOR DO TRABALHO, 2005)

Compartilhando desse entendimento, o Tribunal de Justiça do Estado de Minas Gerais, por meio do Provimento no 075/02 (Conjunto Corregedoria Geral de Justiça e $2^{\text {a }}$ Vice-Presidência), obriga o delegado prestes a deixar o cargo, ainda que exercido em caráter precário, a obrigação de quitar todos os contratos de trabalho antes do ingresso do sucessor (artigo $2^{\circ}$, inciso IV), haja vista ter recebido emolumentos durante o período em que exerceu a titularidade.

No mesmo sentido, o Conselho de Magistratura do Tribunal de Justiça do Rio Grande do Sul, por meio da Resolução no $110 / 94$, condicionou o pedido de remoção, permuta ou aposentadoria dos titulares de cartórios judiciais e ofícios extrajudiciais à comprovação da quitação das obrigações trabalhistas.

Verifica-se, portanto, que a ausência do cumprimento dessas diretrizes deveria culminar na responsabilização do antigo delegado pelo pagamento dos créditos trabalhistas inadimplidos e não do novo titular ou, em última análise, do próprio Poder Público, que deixou de fiscalizar a satisfação desses créditos, tanto durante como ao final do exercício da atividade pelo sucedido. Entender pela responsabilização do novo titular, legitimamente aprovado por concurso público, consistiria verdadeiro atentado contra o mandamento constitucional previsto no artigo 236 e irradiado na legislação supramencionada.

\section{A sucessão trabalhista nas atividades notariais e registrarias: enfoque jurisprudencial e doutrinário}

A ocorrência de sucessão trabalhista nas atividades notarial e registrária é questão controvertida tanto no âmbito doutrinário como jurisprudencial, embora prevaleça, sobretudo na seara jurisprudencial, o entendimento de que apenas se pode falar em sucessão trabalhista quanto não houver solução de 
continuidade na prestação laboral. Significa dizer que apenas ocorre sucessão trabalhista quando o novo titular se aproveita da força e energia de trabalho do obreiro que busca os efeitos sucessórios.

Integram a vertente contrária à ocorrência da sucessão trabalhista no âmbito das atividades registrárias e notariais, Luciano Martinez, Wellington Luiz Viana Junior, Regnoberto Marques de Melo Junior e Paulo Roberto de Carvalho Rêgo, entre outros. Na vertente favorável à ocorrência da sucessão trabalhista, encontram-se Sérgio Pinto Martins e Vólia Bomfim Cassar.

Luciano Martinez (2011) aponta que o delegado aprovado em concurso público de provas e títulos recebe a unidade cartorária de forma originária, por ato estatal, e não de forma derivada como ocorre na sucessão tradicional, por exemplo, por ato de compre e venda entre particulares. Para o jurista, a responsabilidade pelas dívidas trabalhistas permaneceria com o delegado anterior, nascendo, portanto, um novo contrato de trabalho com o delegado investido pós-concurso.

Para Wellington Luiz Viana Junior (2004), caso não possa o antigo delegado assumir os débitos trabalhistas, tal responsabilidade deve ser atribuída ao Poder Público, pois, à luz do regime constitucional, a fiscalização da execução da delegação incumbe ao ente público, que não pode negligenciar seu dever fiscalizatório.

Para Melo Junior (2005), os cartórios extrajudiciais não praticam atos negociais, sendo certo que quem os praticam são os notários e registradores através da delegação estatal. Ademais, inexiste transação entre o antigo e o novo titular, incluindo quanto a crédito e débito, justamente porque tais serviços pertencem inquestionavelmente ao Estado.

Segundo Paulo Roberto de Carvalho Rêgo (2004), além do fato de que cartório não é empresa, o novo serventuário assume a serventia de forma originária, por concurso público, não havendo que se falar em solidariedade ou sucessão entre ele e quaisquer dos seus antecessores.

Em contrapartida, aponta Sérgio Pinto Martins (2012) a ocorrência de sucessão entre $o$ atual titular do cartório e o anterior, desde que passe a exercer suas atividades no mesmo imóvel, utilizando-se dos mesmos móveis, 
arquivos e todo o aparato essencial à atividade pertencente ao titular que o precedeu.

Cassar (2011, p. 492) entende que a sucessão alcançará o novo titular, independentemente da continuidade do contrato de trabalho, em razão da característica da obrigação trabalhista propter rem, ou seja, que adere a coisa e a persegue. Entende a jurista que, "apesar do cartório extrajudicial não possuir personalidade jurídica, é parte legítima para configurar no polo passivo ou ativo da relação processual".

Todavia, conforme já apontado, predomina o entendimento jurisprudencial de que há sucessão trabalhista apenas quando houver continuidade da prestação laboral pelo credor em benefício do suposto sucessor, de acordo com o precedente firmado pelos Tribunais:

\begin{abstract}
CARTÓRIO DE SERVIÇOS NOTARIAIS E DE REGISTRO SUCESSÃO DE EMPREGADORES - COMPROVADA INEXISTÊNCIA DE CONTINUIDADE DOS SERVIÇOS PRESTADOS PELO RECLAMANTE (violação aos artigos 10 e 448 da Consolidação das Leis do Trabalho e 39 da Lei no 8.935/94 e divergência jurisprudencial). A sucessão trabalhista ocorre quando há alteração na estrutura empresarial e modificação dos empregadores, porém com a continuidade da prestação dos serviços, passando o sucessor a responder integralmente pelos débitos trabalhistas havidos antes ou após a sucessão, evitando-se desta forma prejuízos aos contratos de trabalho existentes. No caso dos cartórios extrajudiciais, o mesmo entendimento deve ser aplicado na hipótese em que o contrato não tenha sofrido solução de continuidade com a sucessão na titularidade da serventia, como ocorreu no presente caso. Ademais, os titulares de cartórios extrajudiciais são equiparados aos empregadores comuns, tendo em vista a ausência de personalidade jurídica própria dos estabelecimentos, e em face daquele ser responsável pela direção da prestação dos serviços. Assim, alterado o titular da serventia, e não havendo solução de continuidade no contrato de trabalho, ocorre a sucessão trabalhista nos mesmos moldes em que operados em qualquer relação de emprego. Recurso de revista conhecido e provido. (TRIBUNAL SUPERIOR DO TRABALHO, 2013).
\end{abstract}

RECURSO DE REVISTA. CARTÓRIO. SUCESSÃO TRABALHISTA. NÃOCONTINUIDADE DA PRESTAÇÃO DOS SERVIÇOS. A sucessão de empregadores, a teor dos artigos 10 e 448 da CLT, pressupõe alteração significativa na estrutura interna da empresa de forma a afetar os contratos laborais. A intenção do legislador foi a de amparar o trabalhador que desconhece os negócios comerciais e que não sabe sobre quem recai a responsabilidade civil do empreendimento. Importa, portanto, resguardar os seus direitos, ainda que a ruptura contratual tenha ocorrido anteriormente à transação jurídica que ocasionou a sucessão, não olvidando, por óbvio, do direito regressivo que as empresas possuem de buscar na esfera cível as responsabilidades civis livremente pactuadas entre elas. Todavia, em se tratando de serventia cartorial, a jurisprudência

REVISTA DO DIREITO UNISC, SANTA CRUZ DO SUL №. 43 | p.55-72 | MAIO-AGO 2014 
desta Corte orienta-se no sentido de que não há se falar em sucessão de empregadores quando não houver a continuidade da relação de emprego com o novo titular do cartório. Dessa forma, sendo incontroverso nos autos não ter havido a continuidade da prestação de serviço pela reclamante ao novo titular cartorário, a aferição da alegação recursal ou da veracidade da assertiva do Regional depende de nova análise do conjunto fático-probatório dos autos, procedimento vedado nesta instância recursal, nos termos da Súmula no 126 do TST, cuja aplicação afasta a violação legal apontada. Verifica-se, portanto, que a decisão regional foi proferida em consonância com a jurisprudência desta Corte. Recurso de revista não conhecido. (TRIBUNAL SUPERIOR DO TRABALHO, 2014)

E, no mesmo sentido, condicionando a caracterização da sucessão à inexistência de solução de continuidade e ao efetivo proveito do trabalho em favor do novo titular, já se pronunciou o Superior Tribunal de Justiça:

EMBARGOS DE DECLARAÇÃO. RESPONSABILIDADE CIVIL. LEGITIMIDADE PASSIVA AD CAUSAM. Assentada a premissa da responsabilidade individual e pessoal do titular do cartório, é de se reconhecer que só poderia mesmo responder aquele que efetivamente ocupara o cargo à época da prática do fato como lesivo aos interesses do autor, razão pela qual não poderia tal responsabilidade der transferida ao agente público que o sucedeu, afigurando-se escorreita, portanto, a conclusão em que assentado o aresto embargado. (SUPERIOR TRIBUNAL DE JUSTIÇA, 2005)

Prevalece, ainda, o entendimento de que os cartórios extrajudiciais não possuem personalidade jurídica, cabendo ao titular dos serviços notarial e registrário que se aproveitou da prestação laborativa a responsabilidade pela satisfação das obrigações trabalhistas.

Por isso, o registro dos empregados deve ser feito pelo oficial ou notário, no seu nome, e não como se a unidade cartorária fosse a empregadora, justamente porque o cartório é ente despersonalizado e apenas possui inscrição junto ao Cadastro Nacional de Pessoa Jurídica (CNPJ) para o cumprimento de suas responsabilidades perante a Receita Federal. A título de exemplo, os cartórios de registro de imóveis apenas possuem inscrição junto ao CNPJ para fins de Declaração sobre Operações Imobiliárias (DOI), devendo seus oficiais efetuar a Matrícula CEI (Cadastro Específico do INSS) junto à Receita Federal para a contratação de empregados, ainda que a serventia seja inscrita no CNPJ. 


\section{Considerações finais}

A temática da sucessão trabalhista no contexto das atividades notariais e registrárias, embora apresente diversos pontos controversos na perspectiva doutrinária e jurisprudencial, comporta consenso no tocante aos seguintes pontos: (a) o cartório extrajudicial é ente despersonalizado, portanto, não suscetível à contratação de empregados e a responder ou demandar judicialmente, nos termos do artigo 236 da Constituição Federal; (b) apenas ocorrerá sucessão trabalhista quando houver continuidade da prestação laboral em benefício do novo oficial ou notário.

Todavia, embora exista o entendimento de que, na impossibilidade do delegado antecessor assumir os débitos trabalhistas, deve ser atribuída responsabilidade indireta ao Poder Público, a quem cabe a fiscalização dos atos notariais e registrários através do Poder Judiciário, não se tem visto decisões nesse sentido. Sabe-se, porém, que em razão da latência do Princípio da Proteção ao Trabalhador, que norteia as discussões juslaborais, por se entender pela vulnerabilidade do empregado diante da relação de emprego, é possível - e lamentável - que a sucessão trabalhista abandone e se revista de um aspecto mais econômico do que jurídico.

Especificamente naquelas situações em que há solução de continuidade da prestação laborativa, não há que se falar em responsabilização do novo titular (aprovado em concurso público) pelas obrigações trabalhistas referentes a contratos de trabalho extintos em período anterior à outorga, consoante ao entendimento doutrinário e jurisprudencial prevalente. No caso das atividades registrárias, por mais que o antigo empregado tenha aplicado sua energia em favor daquele cartório extrajudicial, essa energia não se prorroga no tempo, já que no caso específico dos cartórios de registro de imóveis a quantidade de clientes não depende diretamente do esforço dos empregados, pois a competência da atividade registrária decorre de prévia delimitação territorial.

Portanto, a pedra de toque da caracterização ou não da sucessão trabalhista é a presença dos requisitos erigidos pela doutrina clássica e 
referendados pela jurisprudência, quais sejam: (a) a transferência total ou parcial da empresa ou do estabelecimento ou a transferência de unidade econômico-jurídica; (b) a continuidade do empreendimento; e (c) a continuidade da prestação de serviços.

No caso dos cartórios extrajudiciais, basta a continuidade da prestação laborativa, pois, ao contrário, a responsabilização do novo titular (aprovado por concurso público) - que não participou da relação de emprego e, por isso, não deu causa ao inadimplemento das verbas trabalhistas e previdenciárias consiste em real afronta ao mandamento constitucional disposto no artigo 236 da Constituição Cidadã.

\section{REFERÊNCIAS}

CASSAR, Vólia Bomfim. Direito do Trabalho. 5. ed. Niterói: Impetus, 2011.

DELGADO, Maurício Godinho. Curso de Direito do Trabalho. 8. ed. São Paulo: LTR, 2009.

MAGALHÃES, Maria Lúcia Cardoso de. A responsabilidade trabalhista dos notários e registradores de imóveis. Revista do Tribunal Regional do Trabalho da 3ª Região, Belo Horizonte, v. 44, n. 74 p. 113-132, jul./dez. 2006.

MARANHÃO, Délio. Direito do trabalho. 11. ed. Rio de Janeiro: FGV, 1983.

MARTINEZ, Luciano. Curso de Direito do Trabalho. 2. ed. São Paulo: Saraiva, 2011.

MARTINS, Sérgio Pinto. Direito do Trabalho. 28. ed. São Paulo: Atlas, 2012.

MEIRELLES, Hely Lopes. Direito Administrativo Brasileiro. 21. ed. São Paulo: Malheiros, 1996.

MELO JUNIOR, Regnoberto Marques de. Da natureza jurídica dos emolumentos notariais e registrais. In: Jus Navigandi, Teresina, a. 9, n. 591,19 fevereiro de 2005.2 Disponível em: <http://jus2.uol.com.br/doutrina/texto.asp?id=6313 > . Acesso em: 10 set. 2014.

MORAES FILHO, Evaristo de. Sucessão nas obrigações e a teoria da empresa. Rio de Janeiro: Forense, 1960. v. 1. 
NASCIMENTO, Amauri Mascaro. Curso de Direito do Trabalho. São Paulo: Saraiva. 26. ed. 2011.

SILVA, Homero Batista Mateus da. Curso de Direito do Trabalho Aplicado: parte geral. Rio de Janeiro: Elsevier, 2009. v. 1.

SILVA, Otavio Pinto e. Da responsabilidade trabalhista do sócio retirante e a segurança jurídica. Revista do Advogado, n. 110, p. 143-148, dez. 2010.

SUPERIOR TRIBUNAL DE JUSTIÇA. Recurso Especial no 443.467: relator Ministro Castro Filho. 21 de novembro de 2005. Disponivel em:<http://sti.jusbrasil.com.br/jurisprudencia/7224725/recurso-especial-resp443467-pr-2002-0079639-8/inteiro-teor-12970820>. Acessado em: 16 jun. 2014.

SÜSSEKIND, Arnaldo. Curso de Direito do Trabalho. Rio de Janeiro: Renovar, 2002.

TRIBUNAL SUPERIOR DO TRABALHO. Recurso de Revista 1368756152004504 1368756-15.2004.5.04.0900: relator(a) Ministra Maria Cristina Irigoyen Peduzzi. 13 de maio de 2005. Disponível em:< http://tst.jusbrasil.com.br/jurisprudencia/1964308/recurso-de-revista-rr1368756152004504-1368756-1520045040900>. Acessado em: 16 jun. 2014. TRIBUNAL SUPERIOR DO TRABALHO. Recurso de Revista 5550039.2005.5.02.0020: relator Ministro Renato de Lacerda Paiva. 26 de março de 2013. Dsiponível em:<http://www.jusbrasil.com.br/diarios/71926728/tst-17-062014-pg-612?ref=home>. Acessado em: 16 jun. 2014.

TRIBUNAL SUPERIOR DO TRABALHO. Recurso de Revista 12519820105120016: relator Ministro Augusto César Leite de Carvalho. 21 de fevereiro de 2014.2 Disponível em:< http://www.jusbrasil.com.br/diarios/71926728/tst-17-06-2014-pg612?ref=home $>$. Acessado em: 16 jun. 2014.

VIANA JUNIOR, Wellington Luiz. Sucessão trabalhista e a delegação de serviços notariais e de registros públicos. Revista do Tribunal Regional do Trabalho da 3" Região, v. 40, n. 70, p. 69-78, jul./dez. 2004. 